\title{
Naming Rites for Naming Wrongs: What We Talk about When We Talk about Woodrow Wilson-CORRIGENDUM
}

Dara Z. Strolovitch and Chaya Y. Crowder

doi: 10.1017/S153759271600133X. Published online by Cambridge University Press, 31 August 2016.

In the original published article by Strolovitch and Crowder, author Chaya Crowder's middle initial was incorrect. This has since been corrected in the original published article.

\section{Reference}

Strolovitch, Dara Z. and Chaya Y. Crowder "Naming Rites for Naming Wrongs: What We Talk about When We Talk about Woodrow Wilson" Perspectives on Politics 14(3): 770-775. doi: 10.1017/

S153759271600133X. 